\title{
MISERÁVEIS, MARGINAIS E MORADIAS
}

Renato Bernardi ${ }^{1}$

Ana Paula Meda ${ }^{2}$

Danieli Aparecida Cristina Leite Faquim ${ }^{3}$

\section{Resumo}

Este artigo estuda a simbologia envolta na moradia que é direito fundamental social, previsto no artigo $6^{\circ} \mathrm{da}$ Constituição Federal de 1988, a partir do Comentário Geral no 4 sobre o Direito à Moradia Adequada. Muitas moradias, porém, são tidas por inadequadas, principalmente e não apenas pelo lugar onde estão localizadas, mas pela capacidade econômico-financeira que elas evidenciam, de modo que referida constatação de inadequação e diferenças materiais passam a ser reconhecidas nas próprias pessoas que ali moram, em uma transferência naturalmente realizada pelo ideário social atrelado ao consumo. Busca-se expor o conceito de moradia adequada e sua disposição no território urbano, objetivando-se apontar como a concretização incompleta do direito à moradia favorece uma lógica de exclusão socioespacial que passa a reconhecer os indivíduos pelas suas diferenças econômicas e não pela igualdade enquanto condição humana única. Destaca-se, então, a miserabilidade e a marginalização em simbiose contínua com a moradia urbana. A pesquisa está centralizada no método dedutivo, a partir de uma abordagem interdisciplinar entre Direito e Sociologia. Tem-se que a moradia e o local em que se encontra são fatores de influência para o reconhecimento social do indivíduo. Logo, há exclusão oriunda do fato de onde e como se mora.

Palavras-chave: Exclusão socioespacial; direitos fundamentais; cidades; moradia adequada; desigualdade.

\section{INTRODUÇÃO}

O presente artigo aborda a realidade dos inúmeros sujeitos em condições precárias, que sobrevivem às margens da sociedade, num contexto de ausência de moradias dignas. A partir do estudo dos direitos fundamentais, com foco no princípio da igualdade, verifica-se a ideia oposta a esse princípio, ou seja, a lógica da

\footnotetext{
${ }^{1}$ Doutor em Direito do Estado pela Pontifícia Universidade Católica de São Paulo - PUC-SP. Professor efetivo dos cursos de Doutorado, Mestrado e Bacharelado da Faculdade de Direito do Centro de Ciências Sociais Aplicadas da Universidade Estadual do Norte do Paraná - UENP, Campus de Jacarezinho. Coordenador do TCC no CCSA-UENP, campus de Jacarezinho. Coordenador e professor dos cursos de Especialização do PROJURIS/FIO.E-mail: bernardi@uenp.edu.br

${ }^{2}$ Mestranda em Ciência Jurídica pela Universidade Estadual do Norte do Paraná (UENP). Integrante do grupo de pesquisa "Intervenção do Estado na Vida das Pessoas - INTERVEPES/UENP". Advogada do Núcleo de Estudos e Defesa dos Direitos da Infância e Juventude (NEDDIJ/UENP).E-mail: anapaula.meda@yahoo.com.br

${ }_{3}^{3}$ Mestranda em Ciência Jurídica pela Universidade Estadual do Norte do Paraná (UENP). Mestranda em Ensino pela Universidade Estadual do Norte do Paraná (UENP). Professora dos cursos de Pós-Graduação e Graduação da Universidade Norte do Paraná. Integrante do "Grupo de Intervenção do Estado na vida das pessoas" - INTERVEPES da Universidade Estadual do Norte do Paraná - UENP, Campus de Jacarezinho. E-mail: danieli_leite@hotmail.com
} 
exclusão socioespacial urbana na construção das desigualdades humanas.

A temática concernente à exclusão por meio do território - moradias aquém da cidade - apresenta relevância social contemporânea, considerando que não apenas restringe direitos fundamentais dos indivíduos, mas, também evidencia a situação daqueles que embora estejam às margens, fazem parte da sociedade, no entanto, na condição de excluídos em razão do lugar onde moram.

Desta forma, a problemática reside na seguinte indagação: pela análise do desenho territorial urbano, é possível constatar que o estigma territorial oriundo da exclusão socioespacial acaba por criar rótulos e marcas que vinculam os moradores ao local e às condições de suas moradias, veiculando uma lógica que edifica desigualdades humanas que, na verdade, surgem de uma diferença econômica?

Considerando que o direito à moradia digna reflete uma sociedade desigual, e que sua ausência fere os direitos fundamentais do ser humano, objetiva-se demonstrar o estigma "humano" criado pela disposição espacial segregatória, partindo da ideia dos direitos fundamentais e de que o princípio da igualdade na vertente de igualdade de condições e oportunidades colabora para emancipação social, inclusive, contemplando o princípio da universalidade, propiciando a promoção de oportunidades igualitárias a todos os indivíduos.

Todavia, a vivência brasileira demonstra uma disparidade de oportunidades ligadas às possibilidades financeiras que, por vezes, podem ser notadas pelo local da moradia. Assim, diante da pergunta suscitada busca-se apresentar também, que os termos miseráveis e marginais ao englobarem o trio com a palavra moradias, revelam dois dos principais estigmas associados ao lugar em que se mora, qual seja, a pobreza em relação de miserabilidade e a criminalidade em simetria com a marginalidade.

Por isso uma lógica da exclusão socioespacial urbana tende a construir barreiras humanas para problemas socioeconômicos ao criar diferenças que não são naturalmente das pessoas entre as pessoas, mas sim das pessoas em relação à possibilidade de consumir e ter bens, nesta razão, tem-se o emprego dos vocábulos miseráveis e marginais.

Logo, no intuito de entender o problema apresentado tornou-se necessária a delimitação de seu estudo que direcionou a abordagem em breves considerações sobre os direitos fundamentais em relação precípua com o princípio da igualdade como base de oportunidades, no sentido de que a efetivação dos direitos fundamentais corrobora para o desenvolvimento digno; a concepção de moradia adequada e sua realidade nas cidades brasileiras até se alcançar uma análise sobre a exclusão territorial e sua interferência nas relações interpessoais e no desenvolvimento de desigualdades "humanas".

Neste viés, o referencial teórico adotado iniciou da concepção de igualdade em Norberto Bobbio e da realização de direito como emancipação democrática em Habermas. Adiante se trabalhou com o Comentário Geral no 4 sobre o Direito à Moradia Adequada do Comitê de Direitos Econômicos, Sociais e Culturais com 
explicação pautada na obra de Nelson Saule Junior intitulada "A proteção jurídica da moradia nos assentamentos irregulares". No intuito de ilustrar a influência do estigma territorial na construção das desigualdades "humanas" em correlação com a capacidade de consumir, tratou-se de utilizar em uma análise interdisciplinar as linhas de pensamento do sociólogo brasileiro Lúcio Kowarick, bem como dos também sociólogos Zygmunt Bauman e Löic Wacquant.

Como forma de solucionar o questionamento proposto, utilizou-se o método dedutivo como método de abordagem, pois que se partiu de uma visão geral acerca dos direitos fundamentais e do princípio da igualdade, adentrando-se no conceito de moradia adequada e sua disposição nas cidades brasileiras e, por fim, tratou-se de trabalhar com a influência da exclusão socioespacial no erigir de desigualdades ditas humanas.

Por fim, para coleta e análise dos materiais pesquisados utilizaram-se como técnicas de pesquisa, a pesquisa indireta documental (Constituição Federal de 1988, Estatuto da Cidade, Comentário Geral no 4 sobre o Direito à Moradia Adequada) e a pesquisa indireta bibliográfica com o emprego de obras referentes aos pesquisadores da temática proposta, bem como de artigos e revistas científicas direcionadas ao assunto e dados obtidos via internet do Instituto Brasileiro de Geografia e Estatística (IBGE), Fundação João Pinheiro e Data Favela.

\section{DIREITOS FUNDAMENTAIS COMO BASE DE IGUALDADE E OPORTUNIDADES}

Em uma sociedade complexa como a contemporânea, os conflitos de interesses exsurgem com maior vigor, em especial, no que concerne aos direitos fundamentais (subjetivos e políticos). O Estado de Direito assume, então, o papel de conformador da convivência social, buscando a harmonia das relações, no propósito único de realização do bem comum (que é a sua finalidade).

Todavia, quando se busca a emancipação social e a igualdade a todos, parte-se dos ensinamentos do filósofo alemão Jürgen Habermas, com os seguintes dizeres:

A emancipação democrática e sua validação pressupõem: a) a participação de todos os interessados, em idênticas condições de argumentação, podendo afirmar, contrapor, interpretar e recomendar, e, b) que todos participem de modo livre (sem coação), verdadeiro (destituído de neurose), não mentindo intencional ou inconscientemente, e conforme as regras postas para o desenvolvimento do discurso. (HABERMAS, 2001)

Perceptível, então, que os obstáculos à emancipação acabam por se relacionar aos efeitos do processo da racionalização e da própria organização do capitalismo, enquanto causas das patologias sociais da sociedade moderna, entre elas, a marginalização de indivíduos que são excluídos a partir de suas condições econômicofinanceiras e que em grande maioria sobrevivem sem o mínimo de dignidade, inclusive, em suas moradias.

Nesse ínterim, pode-se afirmar que inexiste democracia onde a desigualdade impera. 
A igualdade se trata de princípio que possui no seu cerne a vinculação com o princípio da universalidade. Esta, não se confunde com o princípio da igualdade, aliás, não é à toa que o constituinte, no mesmo dispositivo, enunciou que "todos são iguais perante a lei, sem distinção de qualquer natureza." (SARLET, 2015)

No entanto, o princípio da universalidade possui como sujeito ativo todos os indivíduos, independente da raça, credo, nacionalidade, convicção política, podendo pleiteá-lo em qualquer foro nacional ou internacional. Nesse mesmo sentido, Norberto Bobbio afirma:

A igualdade deve ser um valor supremo de uma convivência ordenada, feliz e civil. A justiça se dá quando há em comum a ordem, o equilíbrio e a harmonia. Em outras palavras, se entende por justiça o tratamento igual aos iguais e desigual aos desiguais. Logo, a igualdade de oportunidades ou de chances, faz parte dos fundamentos do Estado de Democracia Social, devendo ser aplicada a todos os membros do grupo social, sem distinção de religião, sexo, classe social, etc... De tal modo, uma desigualdade se converte em instrumento de igualdade, pelo simples motivo de que corrige uma desigualdade precedente; de modo que a nova igualdade é o resultado da nivelação das duas desigualdades. (BOBBIO, 1977)

Desta maneira, o ideal de igualdade se dá quando ela existe a todos os homens e em todos os aspectos, sobretudo econômicos, ainda que seja um ideal inalcançável. Ainda que a ideia de igualdade seja inatingível, é necessário vislumbrar o fim precípuo de garantir o máximo de efetivação dos direitos fundamentais, sobretudo da igualdade, pois, esta é a expressão dos direitos fundamentais do cidadão.

Frente a esse problema, criou-se o que comumente se denomina de igualdade substancial, ou igualdade material, que visa a equiparação de todos os homens no que diz respeito ao gozo dos direitos, bem como à sujeição a deveres. A igualdade material busca o tratamento uniforme de todos os homens, não perante o direito, mas perante os bens da vida.

Essa igualdade, contudo, em que pese a carga humanitária e idealista que traz consigo, até hoje não se realizou plenamente em nenhuma sociedade, tendo em vista os inúmeros fatores que obstaculizam a sua implementação, principalmente no que se refere às estruturas políticas e sociais.

Canotilho (1999, p. 422-423) diz que o princípio da igualdade possui dimensões subjetivas e objetivas, sendo que essa última funciona como um "princípio jurídico informador de toda a ordem jurídico-constitucional".

No entanto, quando nos referimos a direitos fundamentais, não podemos nos deter apenas ao direito fundamental à igualdade, considerando que ela seja o objeto deste estudo, mas também temos que vislumbrar outros direitos fundamentais que invariavelmente fundamentam a igualdade, especialmente a igualdade de oportunidades e de direitos.

Neste contexto, vale lembrar dos direitos fundamentais à dignidade da pessoa humana e à liberdade. $\mathrm{O}$ primeiro se trata de direito relevante quando falamos de pessoas marginalizadas, miseráveis, excluídas e sem moradias, pois, o direito à moradia contempla a garantia à dignidade da pessoa humana.

Discorrendo sobre a dignidade da pessoa humana e a inclusão social, Ailton Cocurutto (2010, p. 44) observa que 
A dignidade da pessoa humana é preponderantemente jurídica, ao passo que a inclusão do ser na vida social digna não é apenas jurídica, mas fática, e, portanto, de conteúdo político para sua concretização. Na essência, a inclusão ampla e irrestrita das pessoas ao convívio social com igualdade de oportunidades para a realização de uma vida feliz dependerá da atuação dos órgãos dos três Poderes do Estado, mas o enfoque político dessa questão se apresenta primordial. A inclusão social é uma garantia constitucional que apresenta íntima relação com a dignidade da pessoa humana. É possível afirmar que são princípios que caminham juntos e se completam como verdades universais.

Já o direito fundamental à liberdade está frequentemente em paralelo à igualdade e é pressuposto da democracia. Vale lembrar que a liberdade almeja o ideal de convivência social, que permite que ela exista plenamente.

Neste contexto, a valorização da causa da inclusão social com base nos direitos fundamentais à igualdade, dignidade e liberdade, pauta o estudo de viés social na base constitucional a fim de erradicar a exclusão social por meio do território, em que seres humanos são segregados em razão da moradia que dispõem.

E, com isso, evidencia-se uma realidade delineada pela exclusão nas cidades por meio do desenho territorial que não é inclusivo, que faz com que as desigualdades materiais entre os indivíduos sejam transmudadas como desigualdades humanas. Então, não há uma desigualdade humana na essência do ser, mas sim, um desempenho por diferenças econômicas que acabam por refletir a construção de uma diferença entre as próprias pessoas.

Adiante, ver-se-á como a simbologia em torno das moradias pode contribuir para a construção das desigualdades humanas a partir do ambiente urbano que tão somente pelo desenho territorial já produz e reproduz diferenças que acabam por resultar em criações de diferenças propriamente humanas, quando, na verdade, são apenas de feitio econômico.

\section{MORADIAS: PERSPECTIVA JURÍDICA E URBANA}

Morar é uma necessidade humana básica com influência direta na qualidade de vida das pessoas. Sarlet, nesse sentido, (2014, p. 267) pontua "que o direito à moradia tem sido incluído até mesmo no elenco dos assim designados direitos de subsistência, como expressão mínima do próprio direito à vida”.

Além da estrutura física que protege das intempéries, o conceito de moradia adequada engloba um conjunto de requisitos que se efetivados tendem a trazer melhorias tanto para o indivíduo como para a cidade e a sociedade, pois que se baliza como uma igualdade de necessidades mínimas atendidas.

Logo, desde o ano 2000, por intermédio da Emenda Constitucional no 26, a moradia é considerada direito social previsto no artigo $6^{0^{4}}$ da Constituição Federal de 1988, de maneira que sua efetividade - em

\footnotetext{
${ }^{4}$ Art. 6o São direitos sociais a educação, a saúde, a alimentação, o trabalho, a moradia, o transporte, o lazer, a segurança, a previdência social, a proteção à maternidade e à infância, a assistência aos desamparados, na forma desta Constituição.
} 
consonância com os objetivos fundamentais da República Federativa do Brasil, principalmente no que tange à norma inserta no artigo $3^{\circ}, \mathrm{III}^{5}$ - passou a ser buscada pelo governo brasileiro.

Falar em moradias não significa tão somente restringir-se à ideia de casa e habitação. Pelo contrário, a definição de direito à moradia, conforme o Comentário Geral no 4 sobre o Direito à Moradia Adequada do Comitê de Direitos Econômicos, Sociais e Culturais em interpretação ao artigo 11, item $1^{6}$ do Pacto Internacional de Direitos Econômicos, Sociais e Culturais é completa ao entender que a moradia adequada compreende a realização de sete componentes.

Destarte, de acordo com o Comentário mencionado e, através da interpretação de Nelson Saule Junior (2004, p. 103-105), pode-se afirmar que o conceito de moradia adequada envolve a conjugação dos seguintes elementos: segurança jurídica da posse, disponibilidade dos serviços, materiais, benefícios e infraestrutura, gastos suportáveis, habitabilidade, acessibilidade, localização e adequação cultural.

Cabe, neste momento, entender o que significam referidos elementos para que seja viável perceber a amplitude do direito à moradia adequada. Tem-se que a segurança jurídica da posse é o primeiro componente de importância substancial na proteção das moradias, pois garante a permanência no local de morada.

Traduz-se, com isso, que toda pessoa tem o direito de não sofrer arbitrariedades na sua posse seja advinda de particulares quanto oriundas do Poder Público, no sentido de que se garanta amparo legal contra despejos forçados, considerando também a atuação dos Estados-membros no intuito de impedir o cometimento de ilicitudes quanto à posse, seja consequência de propriedade, de aluguel, de ocupação ou de outras formas (SAULE JUNIOR, 2004, p. 103).

Na elucidação de uma realidade afeta à insegurança jurídica da posse, Raquel Rolnik observa que as tramas de poder embutidas nas relações sociais acabam por determinar decisões que não tendem a proteger a posse, ao passo que estão engendradas em perspectivas institucionais e econômicas já envoltas de formas preestabelecidas de atuação:

Fundamentalmente, a insegurança da posse é uma questão de economia política - leis, instituições e processos de tomada de decisão relacionadas ao acesso e ao uso da moradia e da terra são atravessados pelas estruturas de poder existentes na sociedade. Assim, tanto as formas de gestão do solo como as estratégias de planejamento urbano têm uma enorme incidência sobre as possibilidades de acesso - ou bloqueio - à terra urbanizada para os moradores de menor renda. É no interior desta trama jurídico-administrativa que se tecem os mecanismos de inclusão/exclusão na cidade. (2015, p. 152)

Ainda que a segurança jurídica da posse deva prevalecer como necessária para realização da moradia

\footnotetext{
${ }^{5}$ Art. $3^{\circ}$ Constituem objetivos fundamentais da República Federativa do Brasil: III - erradicar a pobreza e a marginalização e reduzir as desigualdades sociais e regionais;

${ }^{6}$ 1. Os Estados Partes do presente Pacto reconhecem o direito de toda pessoa a um nível de vida adequando para si próprio e sua família, inclusive à alimentação, vestimenta e moradia adequadas, assim como a uma melhoria continua de suas condições de vida. Os Estados Partes tomarão medidas apropriadas para assegurar a consecução desse direito, reconhecendo, nesse sentido, a importância essencial da cooperação internacional fundada no livre consentimento.
} 
adequada, percebe-se que a visão acerca da moradia enquanto patrimônio torna a gestão, os arranjos institucionais e decisões em prol de sua proteção discursos perdidos à mercê das razões e importâncias econômicas, quando sequer tais discursos chegam a ser expostos. Inicia-se uma das formas de exclusão na cidade em relação com o desrespeito ao direito à moradia.

Adiante, a disponibilidade dos serviços, materiais, benefícios e infraestrutura diz respeito aos serviços primordiais que toda moradia deve oferecer, como obtenção constante à água própria para consumo, energia elétrica, instalações sanitárias, formas de conservação de alimentos, coleta de lixo e serviços de emergência (SAULE JUNIOR, 2004, p. 103). Na mesma linha de pensamento, Odoné Serrano Junior (2012, p.50) esclarece acerca da interdependência entre a moradia e outros bens jurídicos essenciais à dignidade humana:

A moradia envolve os direitos à saúde e à integridade física e, em casos extremos, o próprio
direito à vida, afetados quando a pessoa não tem acesso a uma morada que lhe assegure o
atendimento de suas necessidades básicas ou lhe assegure um mínimo de segurança porque
desprovida de saneamento básico (serviços de água, esgoto e limpeza urbana) e/ou por ser
exercida em edificação precária, improvisada, mal construída, sem estabilidade da estrutura
física (materiais de baixa qualidade e/ou falta de emprego das técnicas construtivas corretas
e/ou edificação em locais inadequados, ensejando graves riscos de acidentes graves ou fatais
ou de aquisição de doenças.

Como terceiro elemento consagra-se os gastos suportáveis com a morada que, dentro da órbita das despesas básicas de subsistência, não devem ser exorbitantes a ponto de prejudicar outros gastos como alimentação e vestuário. Nesse sentido, Saule Junior (2004, p. 104) observa que "Os custos financeiros pessoais ou habitacionais associados com a moradia devem estar em tal nível que a realização e a satisfação de outras necessidades básicas não sejam ameaçadas nem comprometidas".

Mais dois elementos que compõem o direito à moradia adequada são a habitabilidade e a acessibilidade. A primeira tem relação direta com o fato de a moradia ser habitável, ao passo que deve proporcionar uma estrutura física que proteja dos fenômenos naturais como, por exemplo, chuva, vento, umidade, frio, calor, tempestades, entre outras circunstanciais naturais (SAULEJUNIOR, 2004, p. 104).

Já a acessibilidade vincula-se com a ideia da moradia ser direito ao alcance de todas as pessoas, por se entender que tem relação com um direito básico de sobrevivência digna. Desse modo, a moradia adequada deve ser garantida também para as minorias ou grupos desfavorecidos, conforme corrobora Nelson Saule Junior ao exemplificar (2004, p. 104-105) "as pessoas idosas, as crianças, os deficientes físicos, os portadores de doenças terminais, os HIV-positivos, as pessoas com problemas médicos persistentes, os doentes mentais, as vítimas de desastres naturais, os grupos que vivem em áreas de risco, entre outros".

Por fim, mais dois componentes podem ser elencados como integrantes do direito à moradia adequada, quais sejam, localização e adequação cultural. A localização, característica importante de uma moradia adequada, deve oferecer às pessoas que ali habitam o acesso permanente "às opções de emprego, ao transporte, aos serviços 
de saúde, às escolas, às creches e outros serviços públicos essenciais" (SAULE JUNIOR, 2004, p. 105), o que figura a necessidade da moradia estar incorporada à cidade, mas não existir aquém dela, a partir de uma exclusão socioespacial que leve ao estigma pelo território.

A adequação cultural, por sua vez, está vinculada à identidade e à diversidade cultural através da construção e dos materiais empregados na edificação da moradia, conforme as tradições mantidas em determinada localidade, ou seja, se existe uma expressão cultural por meio das casas, esta deve ser mantida e incentivada pelo poder público como forma de inclusão social associada à ideia de pertença a um grupo identificado.

Logo, "a expressão da identidade e da diversidade cultural da moradia deve ser apropriadamente assegurada na maneira como são construídas as moradias, nos materiais de construção usados e nas políticas em que se apóiam" (SAULE JUNIOR, 2004, p. 105). Com isso é possível notar que o direito à moradia, não apenas vislumbrado como patrimônio e não restrito à dimensão de casa é prioridade existencial para o desenvolvimento humano saudável.

Desta maneira, a partir de uma ideia orientada pelo princípio da igualdade, bem como pelo universalismo, enquanto característica dos direitos fundamentais pode-se pensar que a obtenção da moradia adequada seja algo comum à maioria dos indivíduos que habitam nas cidades, justamente por derivar de uma imprescindibilidade básica de existência digna:

a moradia adequada pressupõe medidas que extrapolem a lógica mercadológica, instando do estado políticas públicas sociais, ambientais e de infraestrutura e à sociedade o reconhecimento desse direito não só como uma garantia, mas como um direito inerente à condição humana quanto ao uso da terra. (MENDES, 2013, p. 114)

Contudo, ainda que o direito à moradia, enquanto direito fundamental social, seja necessário para vida humana, dentro de uma perspectiva urbana é notável que as grandes cidades brasileiras não comportam uma totalidade de moradias adequadas, essencialmente no que diz respeito às famílias economicamente desfavorecidas que acabam por ser excluídas em favelas e/ou em assentamentos informais desprovidos de qualquer estrutura:

As cidades na globalização também se tornaram objetos de estudos específicos, já que a reestruturação produtiva tem forte impacto sobre o território, e os ajustes impostos pelo ideário neoliberal enfraqueceram os investimentos em políticas sociais; entre elas figuram as políticas urbanas estruturadoras como: transporte, habitação e saneamento. (MARICATO, 2015, p. 13).

Na elucidação de tal cenário, trazem-se a lume alguns dados oriundos da página online do Instituto Brasileiro de Geografia e Estatística (IBGE) identificada como "Brasil em síntese", especificamente voltada para a temática da habitação. Pelo estudo das informações em conjunção com o aporte teórico apresentado no trabalho, é viável a percepção de que muitas moradias ainda são inadequadas pela falta ou deficiência de algum ou alguns dos sete componentes ora apresentados.

As informações colhidas por intermédio do acesso ao site do IBGE são fruto da Pesquisa Nacional por vol.10, no. 04, Rio de Janeiro, 2017.pp. 2413-2429 
Amostra de Domicílios - PNAD que tem por espoco gerar informações sobre as condições de moradia da população como saneamento básico dentre outras características habitacionais.

De acordo com referidos dados, em 2014 apenas 0,3\% dos domicílios brasileiros não continham iluminação elétrica, ao passo que em 2004 o percentual obtido era de 3,2\%. Quanto à coleta de lixo domiciliar houve crescimento, passando de 84,6\% dos domicílios em 2004 para 89,8\% dos domicílios em 2014. Interessante averiguar que quanto ao esgotamento sanitário adequado (rede geral ou fossa séptica) ocorreu um aumento de 2013 (76,2\%) para 2014 (76,8\%), com diminuição dos domicílios com fossa séptica, pois que em 2004 os domicílios atendidos por rede geral de esgoto constavam no patamar de 47,9\%, sendo que em 2013 tal número subiu para 58,2\%, caindo para 57,6\% em 2014.

Diante do resumo dos dados aqui mencionados cabe dizer que a moradia, quanto à estrutura de materiais e serviços ainda se mostra em considerável precariedade, o que tende a torná-la inadequada. Ainda assim, é possível observar que o déficit habitacional está essencialmente vinculado às pessoas economicamente desfavorecidas.

Para tanto, outros dados podem ser analisados através de estudos desenvolvidos pela Fundação João Pinheiro (FJP) em publicação intitulada "Déficit habitacional no Brasil 2013-2014, que pesquisou a relação entre o déficit habitacional brasileiro e a faixa de renda, concluindo que a deficiência está concentrada na faixa de renda de até três salários-mínimos (2016, p. 35).

No ano 2013 a deficiência habitacional em tal faixa de renda estava em 83,4\% do déficit habitacional urbano do país. No período de 2013 a 2014 houve aumento de 0,5 ponto percentual na faixa de três saláriosmínimos, de maneira que em 2014 constava em 83,9\% do déficit habitacional urbano do país. Notou-se que nas regiões Norte e Nordeste o déficit em referida faixa de renda diminuiu de 79,6\% e 89,9\% em 2013, para 79,5\% e $88,2 \%$ respectivamente (2016, p. 35).

Nas regiões Sudeste, Sul e Centro-Oeste houve uma elevação do déficit habitacional relativo à população que aufere até três salários mínimos. Em 2013, respectivamente comportava 82,3\%, 76,8\% e 83,5\%, aumentando para $83,7 \%, 78,2 \%$ e $83,9 \%$ em 2014 (2016, p. 35).

A faixa de mais de três até cinco salários-mínimos estava no patamar de 9,9\% do déficit habitacional urbano no Brasil, enquanto em 2014 o índice foi reduzido para 9,7\%. No que tange às outras faixas de renda, quais sejam, mais de cinco até dez salários-mínimos e mais de dez salários, percebeu-se que "Com exceção da faixa de renda mais baixa (até três salários-mínimos), as demais apresentam ligeira redução no percentual de 2013 para 2014." (2016, p.35).

Observa-se que o déficit habitacional atinge aqueles que mais precisam ter seus direitos sociais garantidos, como é o caso da moradia. Logo, a pobreza, correlata ao termo miseráveis, pode ser vislumbrada 
quando da análise do tema morar, uma vez que a inadequação ou a ausência de moradias, por vezes, liga-se à condição econômica. Em virtude disso, passam a surgem conflitos pela terra nas cidades de modo que alcançam o Poder Judiciário.

O Judiciário, entretanto, tende a hierarquizar os direitos e sob um ponto de vista ideológico é viável traçar em analogia aos conflitos do campo, a forma de tratamento dado aos conflitos pela terra em âmbito geral quando em juízo:

O intérprete que deixa de lado a função social da propriedade na solução dos conflitos agrários não o faz por mera inaptidão para o raciocínio jurídico ou por ignorância, mas por uma decisão interessada. Se for lido por uma ideologia menos conformada aos valores do sistema e à lógica proprietária, uma ideologia voltada, por exemplo, aos valores da dignidade humana e da função social da propriedade, o texto constitucional torna insustentável as leituras civilistas e penalistas que os conflitos do campo têm recebido do Judiciário. (MELO, 2012, p.110, grifos do autor)

Não se quer dizer, contudo, que o direito à moradia é absoluto em todos os casos concretos, mas que precisa ser sopesado quando há propriedade que não atende à função social:

Não significa dizer que a melhor solução seja julgar em desfavor do proprietário, [...], mas deve-se lembrar que o seu direito é limitado ao atendimento da função social da propriedade. [...], no entrechoque do direito fundamental e individual de propriedade com o direito social à moradia, deve prevalecer a garantia do direito social à moradia, quando o proprietário não desempenha uma função social sobre a sua propriedade. Neste último caso, deverá ser protegido o direito do possuidor que desempenha sobre o imóvel alheio função social pela moradia. (PAGANI, 2009, p. 192)

O reconhecimento pela imprescindibilidade do direito à moradia influi para o desenvolvimento humano digno em atenção à própria formação equitativa da ordem urbanística que é ponto evidente tratado na Constituição Federal de 1988 ao expor no Capítulo II a Política Urbana como assunto de primordial necessidade na formação e readequação das cidades brasileiras.

Vê-se, com isso, que se o déficit habitacional está concentrado na faixa de renda mais baixa, até três salários-mínimos, há uma relação significante entre moradia e condição econômico-financeira. Quando um conflito fundiário urbano chega ao Poder Judiciário, ao invés de tentar ser solucionado em seu amálgama central, é "resolvido" sem qualquer atenção com o direito à moradia, continuando uma lógica de exclusão que é reafirmada pelo poder representante do próprio Estado, que deveria ser o primeiro interessado em concretizar os objetivos contidos na Constituição Federal de 1988.

\section{A EXCLUSÃO SOCIOESPACIAL E SEUS REFLEXOS NA CONSTRUÇÃO DAS DESIGUALDADES HUMANAS}


A convivência humana é um desafio em expansão. As relações interpessoais tornaram-se mais complexas assim como a vida nas cidades, de modo que o território urbano tornou-se uma representação evidente da separação eivada nas sociedades: a diferença associada ao poder econômico, quase que como uma compra advinda do olhar pela aparência, sustentada na superficialidade de estigmas que proliferam um liame de preconceitos e medos:

Áreas habitadas são descritas como "urbanas" e chamadas de "cidades" se forem caracterizadas por uma densidade relativamente alta em termos de população, interação e comunicação. Hoje, elas também podem ser os lugares em que inseguranças socialmente concebidas e incubadas são confrontadas de uma forma altamente condensada e, portanto, particularmente tangível. Também é nos lugares ditos "urbanos" que a elevada densidade da interação humana coincidiu com a tendência de o medo nascido da insegurança buscar e encontrar escoadouros e objetos sobre o qual se possa descarregar - embora essa tendência nem sempre tenha sido a característica distintiva desses lugares. (BAUMAN, 2007, p. 77)

Pessoas passaram a ter mais medo de indivíduos diferentes que advêm de lugares possivelmente tidos por suspeitos como uma favela, por exemplo, ou aqueles que ocupam um terreno de propriedade alheia, rotulados como invasores. Com isso, viver nas metrópoles brasileiras é uma disputa e uma conquista constante pela vida, pelo poder e pelo território. $\mathrm{O}$ espaço tem seu preço que automaticamente é transmudado para aquele que o ocupa.

Dessa maneira, pode-se afirmar que os próprios espaços urbanos, bem como a moradia em si carregam uma simbologia agregada ao território e àquilo que o indivíduo possui no local: as condições de habitação, a localidade da moradia, a infraestrutura pública oferecida nas proximidades da casa, bairro violento, bairro nobre, centro velho, assentamento irregular. Da onde você vem é uma pergunta que sintetiza sobremaneira o que as pessoas podem pensar sobre outras pessoas que as perpassam nas ruas da cidade.

Mas para que seja possível demonstrar que existe um estigma oriundo do lugar, emprega-se neste estudo uma pesquisa realizada pelo instituto Data Favela e divulgada por intermédio de sua página online, na qual se constata que aproximadamente $30 \%$ dos moradores de favelas já se sentiram discriminados por determinados fatores. Referida pesquisa nomeada como Radiografia das Favelas foi a primeira realizada pelo instituto.

Segundo tais dados, 59\% dos moradores das comunidades concordam que quem mora em comunidades da periferia é discriminado, sendo que para $32 \%$ das pessoas a discriminação decorre da cor da pele e para 30\% morar na favela mostrou-se como a razão da diferenciação. Neste tom, 66\% dos entrevistados não desejavam sair da favela e 94\% dessas pessoas disseram estar felizes ao morarem em tal lugar.

Percebe-se a partir das informações correlacionadas que 30\% dos moradores entrevistados entendem que a discriminação sofrida foi consequência do lugar da moradia dentro do desenho urbano. É como se houvesse uma associação negativa que tolhesse qualquer aspecto positivo encontrado em mencionados locais. Logo, quanto a uma abordagem acerca do protagonismo advindo da favela e das pessoas que ali habitam, pode-se 
mencionar um ponto contraditório.

Ao mesmo tempo em que as pessoas moradoras de favelas podem ser rotuladas como pobres, economicamente falando e, marginais, pois que em contato direto com a criminalidade de acordo com a visão midiática transmitida, constroem-se "aparências sociais", como se fosse possível dividir as cidades e os indivíduos em bons e ruins. No entanto, são essas mesmas pessoas que cada vez mais se lançam no mercado consumista. A incongruência está justamente na questão de que, se por um lado a economia ajuda na estigmatização humana, por outro precisa das pessoas também estigmatizadas para alimentar o mercado consumista:

Quem comanda o processo de mudança no Brasil? Quem lança tendências? Quem aprova ou reprova um programa social, uma linha de eletrodomésticos ou uma nova música? Resposta simples: são os ingressantes no mercado de consumo, de modo especial os 11,7 milhões de habitantes das favelas, grupo que equivale a $6 \%$ da população brasileira. Com vigor, eles movem a onda transformadora que varre o país no século XXI. De modo ligeiro, essas pessoas constituem novos padrões de consumo, reinventam atividades econômicas $\mathrm{e}$ contribuem decisivamente para definir o perfil cultural do país dos emergentes. Se compusessem um estado, as favelas seriam o quinto mais populoso da federação, capaz de movimentar 63 bilhões de reais a cada ano. Ainda assim, o universo da favela parece invisível à grande mídia, aos intelectuais e à boa parte dos planejadores de negócios, que ignoram e desprezam seu poder transformador. (MEIRELLES; ATHAYDE, 2014, p. 28)

Neste viés, nota-se que morar em uma favela pode não ser sinônimo de miserabilidade, mas sim uma escolha que se relaciona com a identidade, com o sentimento de pertença e como forma de expressão cultural. Pela leitura da passagem apresentada torna-se evidente que as favelas têm um protagonismo que muitas vezes é inexplorado ou esquecido.

Ressalta-se ainda que as favelas exercem importante influência social e econômica ao passo que ditam conceitos que são absorvidos pela sociedade, mas que tendem a ser inferiorizados, resultando em um estigma territorial que acaba por embaraçar toda uma formação sólida das relações entre os atores sociais, o que prejudica a construção de respeito ao indivíduo enquanto dotado de condição humana única.

O estigma do território, nesta linha de raciocínio, contribui para formação de preconceitos e isso acaba desgastando os vínculos sociais ao fragilizar as relações interpessoais e criar na pessoa moradora da favela uma noção de excluído da cidade e da sociedade:

Em primeiro lugar, o sentimento de indignidade pessoal que ele carrega assume uma dimensão altamente expressiva da vida cotidiana, que colore as relações interpessoais e afeta negativamente as oportunidades nos círculos sociais, nas escolas e nos mercados de trabalho. Em segundo, observa-se uma forte correlação entre a degradação simbólica e o desmantelo ecológico dos bairros urbanos: áreas comumente percebidas como depósito de pobres, anormais e desajustados tendem a ser evitadas pelos de fora, "assinaladas" pelos bancos e corretores de imóveis, desdenhadas pelas firmas comerciais e ignoradas pelos políticos, tudo isso colaborando para acelerar-lhes o declínio e o abandono. Em terceiro, a estigmatização territorial origina entre os moradores estratégias sociófobas de evasão e distanciamento mútuos e exacerba processos de diferenciação social interna, que conspiram em diminuir a confiança interpessoal e em minar o senso de coletividade necessário ao engajamento na construção da comunidade e da ação coletiva. (WACQUANT, 2005, p. 33) 
Wacquant (2005, p. 33) acrescenta que "existe o estigma de ser pobre no seio de uma sociedade rica, na qual a participação ativa na esfera do consumo tornou-se condição sine qua non da dignidade social - um passaporte para a cidadania, mesmo entre os despossuídos". Vê-se que a favela liga-se a um ideário de exclusão, pois que geralmente as pessoas são vistas como miseráveis e marginalizadas, ainda que venham se apresentando como consumidores emergentes.

Tal estigma pode estar vinculado ao fato de tais moradores ainda não representarem os consumidores que a sociedade em si aprova e acolhe, de modo que "os pobres ou não participam do mercado de consumo (são consumidores falhos) ou não consomem na proporção que o mercado deseja (são os maus consumidores)." (CAMBI, 2016, p. 547, grifos do autor).

Bauman (2008, p.19) ao descrever o que denomina "sociedade de consumidores" observa a influência do consumismo nas relações humanas por meio do padrão, logo, o que é diferente de mim, já que não pode consumir os mesmos produtos, desvia-se do padrão estabelecido e não há reconhecimento social. O território que representa pobreza e incômodo, pela noção aparente de que se buscam as mesmas coisas materiais, mesmo não havendo poderio econômico para tanto, estigmatiza na medida em que surge o receio e a insegurança de que o desconhecido socialmente interfira no bem-estar alheio para alcançar os mesmos produtos frutos do consumo, então, o surgimento de marginais/criminosos oriundos da "parte pobre da cidade":

Os encontros dos potenciais consumidores com os potenciais objetos de consumo tendem
a se tornar as principais unidades na rede peculiar de interações humanas conhecida, de
maneira abreviada, como "sociedade de consumidores". Ou melhor, o ambiente existencial
que se tornou conhecido como "sociedade de consumidores" se distingue por uma
reconstrução das relações humanas a partir do padrão, eà semelhança, das relações entre os
consumidores e os objetos de consumo. Esse feito notável foi alcançado mediante a
anexação e colonização, pelos mercados de consumo, do espaço que se estende entre os
indivíduos - esse espaço em que se estabelecem as ligações que conectam os seres humanos
e se erguem as cercas que os separam.

Não se identifica a pessoa humana. Percebe-se a aparência, o risco e o medo da convivência nos mesmos locais, pois todo indivíduo tornou-se perigo e segurança. Assim, "Nas aglomerações urbanas predominam o anonimato, a falta de contato social e o sentimento de impotência. $\mathrm{O}$ sujeito não é ninguém, não é visto nem ouvido. É mais um no rebanho. Essa dessubjetivização [...], compõe o enredo de muitas narrativas dos deprimidos." (BOULOS, 2015, p. 61-62).

Continuamente, não só o território, mas a moradia também carrega doses de simbologia. Para Lúcio Kowarick (2000, p.90) tal fato é perceptível do ponto de vista da casa própria ao significar no imaginário social uma conquista resultante de trabalho e dignidade, como prova da vitória na vida:

Além de certa segurança contra as mazelas do sistema econômico e do acúmulo material, a casa própria mais facilmente conduz a uma configuração sociocultural apoiada nos símbolos de sucesso de quem venceu na vida. É a vitória de uma moralidade que valoriza a família 
unida, pobre porém honesta, o trabalho disciplinado, enfim, a vitória da perseverança que leva à conquista da propriedade.

No desenvolvimento de referido pensamento, o autor acrescenta que:

vale insistir nos significados simbólicos da moradia. Lar, privacidade: sobre a casa própria se ilumina o imaginário da disciplina e do sucesso, enquanto sobre os cortiços e as favelas despenca a pecha de uma pobreza culpabilizada pelo fracasso, que precisa viver amontoada, onde se misturam sexos e idades. Tidos e havidos como locais que favorecem hábitos duvidosos, brigas e desorganização familiar, espaço de promiscuidade, as habitações coletivas, com seus múltiplos e congestionados cubículos, e as favelas, por expor a pobreza numa situação de flagrante ilegalidade urbana, são particularmente estigmatizadas como locais de imoralidade, e daí o passo para a suspeição de vício e até de criminalidade. (KOWARICK, 2000, p. 91)

Neste prisma, pode-se entender que tanto o território quanto a moradia estão incorporados de simbologias inclusivas ou exclusivas, de acordo com a condição em que se apresentam. Morar em favelas ou em ocupações irregulares, conforme aponta Lúcio Kowarick ao denotar as habitações coletivas e expor o termo favela, enseja morar em um "espaço de promiscuidade" consubstanciado com a ideia de ilegalidade urbana, daí a pobreza e a marginalidade - em nexo com a criminalidade - encontradas em lugar comum:

embora o estigma territorial transforme habitantes em criminosos ou em violadores da ordem urbanística, o "crime" em questão - como em infinitos outros casos é não obedecer ao planejamento, locus onde se definem as formas permitidas - ou proibidas - de organizar o espaço. (ROLNIK, 2015, p. 174, grifo da autora)

Destarte, não se tratam de indivíduos miseráveis e marginais dentro da ótica da condição humana única. Todavia, são indivíduos miseráveis e marginais dentro da sociedade, ou seja, através da moradia e do território é possível julgar pela miserabilidade e marginalidade ainda que não sejam diferenças naturais, mas sim desigualdades econômicas transferidas como "humanas" e adicionadas na figura da pessoa que, em segundo plano, é reconhecida como humana.

\section{CONCLUSÃO}

Diante dos argumentados apresentados pode-se constatar que a efetivação dos direitos fundamentais comporta uma base de igualdade e oportunidades, vez que os indivíduos tendem a adquirir emancipação democrática, mas que necessário adotar o princípio da igualdade como um “valor supremo" angariado por Bobbio, na medida em que deve existir a igualdade, as oportunidades e a igualdade de oportunidades como essencialidade do Estado Democrático de Direito.

O direito à moradia, enquanto direito fundamental social positivado no artigo $6^{\circ}$ da Constituição Federal de 1988, ao ser conceituado com fundamento no Comentário Geral no 4 sobre o Direito à Moradia Adequada, elenca uma série de componentes que integram a moradia adequada/digna, ao passo que um deles é a localização.

A localização tem relação direta com a ideia de segregação socioespacial, pois que comumente é 
perceptível na construção do meio ambiente artificial a forma como a sociedade se organiza, se diferencia, se separa, cria barreiras e realça as diferenças de poderio econômico. Denota-se, desse modo, que tanto o território quanto a moradia são portadores de uma simbologia alimentada socialmente, como o ideário da pobreza e da marginalidade nas favelas e nos assentamentos ilegais.

Com isso, a exclusão nas cidades, por meio do desenho territorial que não é inclusivo, faz com que as desigualdades materiais entre os indivíduos sejam transmudadas como desigualdades humanas. Então, não há uma desigualdade humana na essência do ser, mas sim desempenhada por diferenças econômicas que acabam por refletir a construção de uma diferença entre as pessoas.

Por exemplo, um morador de favela ou de um bairro perigoso, bem como de uma ocupação irregular de uma grande cidade pode ser visto como um miserável e marginal simplesmente pelo local em que mora, sem se considerar sua igualdade humana que é idêntica a de qualquer outra pessoa.

Assim, o que difere são as condições econômicas que acabam por "selecionar" padrões e "construir" uma diferença que passa a ser reconhecida nos próprios seres humanos, como se naturais fossem, quando, na verdade, são arquitetadas por uma lógica segregatória que começa pelo território e pela moradia e estigmatiza o ser como objeto de valor embutido no patrimônio.

\title{
MISERABLE, MARGINAL AND HOUSING
}

\begin{abstract}
This article explores the symbolism wrapped in housing that as a social fundamental right contained in article 6 of 1988 Federal Constitution should include a minimum of dignified conditions for human disposition in such an environment in accordance with the requirements of General Comment No. 4 of about the right to adequate housing. It turns that in fact many housing are taken by inadequate, especially not jus for the place where they are located but for the economic and financial capacity that they show, so that the said finding of inadequacy and material differences become to be recognized in people that live there, in a kind of transfer naturally course conducted by social ideology linked to consumption. Thus within the problematic mooted seeks to expose the concept of adequate housing and its disposal in urban territory, so that the objective is to show how the incomplete realization of the right to housing favors a social-spatial exclusion logic that comes to recognize individuals for the their differences in economic power and not for equality as the only human condition. Then it is emphasized that the wretchedness and marginalization in continuous symbiosis with urban housing. Therefore the research is centralized following the deductive method in addition to the documentary and bibliographic research techniques.
\end{abstract}

Keywords: Social Exclusion; Fundamental Rights; Cities; Adequate Housing; Inequality.

\section{REFERENCIAS}

BAUMAN, Zygmunt. Tempos líquidos. Tradução: Carlos Alberto Medeiros. Rio de Janeiro: Jorge Zahar Ed., 
2007

Vida para consumo: a transformação das pessoas em mercadorias. Tradução: Carlos Alberto Medeiros. Rio de Janeiro: Jorge Zahar Ed., 2008.

BOBBIO, Norberto. Igualdade e liberdade. Tradução: Carlos Nelson Coutinho. $3^{\mathrm{a}}$ ed. Rio de Janeiro: Ediouro, 1997.

BOULOS, Guilherme. De que lado você está?: reflexões sobre a conjuntura política e urbana no Brasil. São Paulo: Boitempo, 2015.

CAMBI, Eduardo. Neoconstitucionalismo e neoprocessualismo: direitos fundamentais, políticas públicas e protagonismo judiciário. São Paulo: Almedina, 2016.

CANOTILHO, J.J. Gomes. Direito Constitucional e Teoria da Constituição. 4a ed. Coimbra: Livraria Almedina, 1999.

COCURUTTO, Ailton. Os princípios da dignidade da pessoa humana e da inclusão social. $1^{\text {a }}$ ed. São Paulo: Malheiros, 2008.

DATA FAVELA. Quase 30\% dos moradores de favelas já se sentiram discriminados, diz pesquisa. 2013. Disponível em: <http://datafavela.com.br/quase-30-dos-moradores-de-favelas-ja-se-sentiram-discriminados-dizpesquisa/ >. Acesso em: 18 jun. 2016.

FUNDAÇÃO JOÃO PINHEIRO. Centro de estatísticas e informações. Déficit habitacional no Brasil 20132014. Belo Horizonte, 2016. Disponível em: http://www.fjp.mg.gov.br/index.php/docman/cei/informativoscei-eventuais/634-deficit-habitacional-06-09-2016/file. Acesso em: 17 out. 2016.

HABERMAS, Jürgen. On the Pragmatics of Social Interaction: Preliminary Studies in the Theory of Communicative Action. Translated by Barbara Fultner. Cambridge, Massachusetts: The MIT Press, 2001.

INSTITUTO BRASILEIRO DE GEOGRAFIA E ESTATÍSTICA - IBGE. Brasil em síntese: habitação. Disponível em: <http://brasilemsintese.ibge.gov.br/habitacao.html>. Acesso em: 24 ago. 2016.

KOWARICK, Lúcio. Escritos urbanos. Fotografias: Tomás Rezende. São Paulo: Ed. 34, 2000.

MARICATO, Erminia. Para entender a crise urbana. 1a ed. São Paulo: Expressão Popular, 2015.

MEIRELLES, Renato; ATHAYDE, Celso. Um país chamado favela: a maior pesquisa já feita sobre a favela brasileira. São Paulo: Editora Gente, 2014.

MELO, Tarso de. Direito e ideologia: um estudo a partir da função social da propriedade rural. $2^{a}$ ed. São Paulo: Outras Expressões, Dobra Editorial, 2012.

MENDES, Christiane Keler de Lima. Regularização fundiária urbana para além de um direito social. In.: PAGLIARINI, Alexandre Coutinho; RIBEIRO, Márcia Carla Pereira (coord.). Sociedades e direito. Rio de Janeiro: LMJ Mundo Jurídico, 2013.

PAGANI, Elaine Adelina. O direito de propriedade e o direito à moradia: um diálogo comparativo entre o direito 
de propriedade urbana imóvel e o direito à moradia. Porto Alegre: EDIPUCRS, 2009.

ROLNIK, Raquel. Guerra dos lugares: a colonização da terra e da moradia na era das finanças. $1^{a}$ ed. São Paulo: Boitempo, 2015.

SARLET, Ingo Wolfgang. A eficácia dos direitos fundamentais: uma teoria geral dos direitos fundamentais na perspectiva constitucional. 12a edição. Porto Alegre: Livraria do Advogado Editora, 2015.

Algumas notas sobre a eficácia e efetividade do direito à moradia como direito de defesa aos vinte anos da constituição federal de 1988. In.: FERNANDES, Edésio; ALFONSIN, Betânia. Direito à moradia adequada: o que é, para quem serve, como defender e efetivar. Belo Horizonte: Fórum, 2014.

SAULE JUNIOR, Nelson. A proteção jurídica da moradia nos assentamentos irregulares. Porto Alegre: Sergio Antonio Fabris Editor, 2004.

SERRANO JÚNIOR, Odoné. O direito humano fundamental à moradia digna: exigibilidade, universalização e políticas públicas para o desenvolvimento. Curitiba: Juruá, 2012.

WACQUANT, Löic. Os condenados da cidade: estudos sobre marginalidade avançada. Tradução: João Roberto Martins Filho et al. Rio de Janeiro: Revan; FASE, 2001.2 ${ }^{\text {a }}$ ed. setembro de 2005.

Trabalho enviado em 18 de abril de 2017.

Aceito em 22 de maio de 2017. 